\title{
Rotterdam general practitioners report (ROHAPRO): a computerised network of general practices in Rotterdam, The Netherlands
}

Barend J C Middelkoop, A M Bohnen, J S Duisterhout, A W Hoes, H J C M Pleumeekers, A Prins

\begin{abstract}
Study objective - Dutch public health services are charged with collective preventive care for the population - care that should, by law, be based on epidemiological data. General practices potentially offer important data for this purpose, particularly since more and more use a computer. This study aimed to assess whether it is possible to obtain useful epidemiological data from this source.

Design - In 1990, the Rotterdam Municipal Health Service, in collaboration with the Erasmus University Rotterdam, started a computerised sentinal practice network. The main features of this and a specific small investigation are described. Setting - The following institutions cooperate in the network: Municipal Health Service Rotterdam Area; Departments of General Practice and of Medical Informatics, Erasmus University Rotterdam; Rotterdam District Association of General Practitioners.

Patients - Data are currently collected from 20 general practitioners and $>40000$ patients. In a specific project, the distribution of cardiovascular risk factors in different ethnic groups was compared.

Main results - It was possible to build up a regional epidemiological registration system in this manner. In the cardiovascular project we found striking differences between ethnic groups. The risk profile for Turkish men, in particular, was less favourable. The health service also uses the system to improve cooperation between public health and primary health care (for example, in cervical screening, influenza vaccination).

Conclusion - Computerised general practices offer great possibilities for research and for preventive activities in which public health care and general practitioners can cooperate.
\end{abstract}

\section{( $于$ Epidemiol Community Health 1995;49:231-233)}

Rotterdam District Association of General Practitioners, Rotterdam,

The Netherlands

H J C M Pleumeekers

Correspondence to: Dr B J C Middelkoop. Accepted for publication January 1995

In The Netherlands, the municipal health services are charged with the collective preventive care of their population. ${ }^{1}$ The basis of the preventive activities is - or should be - knowledge of the health of the local population. For this purpose the health services use data from epidemiological research such as health surveys, hospital discharge figures, and specific investigations. Until now, information about primary care has been difficult to obtain.

General practitioners (GPs) play an important role in the Dutch health care system. All inhabitants of The Netherlands are on the list of a GP. When a patient is ill he or she first consults the GP who will then, if necessary, refer them to a specialist and hospital. Many sick patients are not seen by specialists, therefore but by the GP only. Where they are seen by a specialist, the GP retains the role of coordinator of the patient's care and will be advised about findings and treatment plans. GP's therefore are a potentially important source of epidemiological information.

A major problem has always been the accessibility of these data. In the 1980s, many Dutch GPs started using computers to record patient information. Currently, over $75 \%$ use a computer, and more than $25 \%$ use the socalled module, the part of the program used to record medical data. ${ }^{2}$

Against this background, the Municipal Health Service Rotterdam decided in 1990 to start a registration system, using computerised practices in the region. The collaboration of the Departments of General Practice and Medical Informatics of Erasmus University Rotterdam was also obtained. This sentinel practice network offers epidemiological information to the health service and the possibility of scientific research by the university departments. The network is called: "Rotterdam's HuisArtsen project" (ROHAPRO) which means Rotterdam General Practitioners Project.

Other Dutch university departments of general practice have built up comparable registration networks, ${ }^{34}$ but nowhere else is the public health service involved in such a network. The cooperation between the Municipal Health Service Rotterdam area, the Department of General Practice, Erasmus University Rotterdam, and the participating GP is unique in The Netherlands.
Data collection

Data are currently collected from 14 practices with $20 \mathrm{GPs}$, including more than 40000 patients. Four times a year the GPs send a floppy disk to the municipal health service. This contains two types of data on their patients - background variables and medical data. 
BACKGROUND VARIABLES

The background variables are the following:

- Patient number (assigned by the practice computer);

- Sex;

- Age;

- Postal code;

- Country of origin;

- Ethnic background;

- Form of insurance (national health or private: every Dutch citizen with an income below a certain level is insured by the national health insurance; private insurance is required above that income level);

- Level of education;

- Entrance date to the GP practice;

- Date of leaving the practice if this has occurred;

- Reason for leaving.

MEDICAL DATA

The medical data mainly consist of the disorders recorded on the so-called "problem list" of major social and medical disorders. These problems include: chronic problems (that is, lasting more than half a year) and problems that are of permanent importance in themselves or because of possible complications. Problems that recur more than three times within half a year are also listed. The problems are recorded with the date of first diagnosis, the date of ending (if applicable), the GP's description of the problem, and the diagnoses, coded according to the International Classification of Primary Care (ICPC) ${ }^{6}$ Other medical data include laboratory findings, blood pressure, body mass index, number of cigarettes smoked daily, and average daily alcohol intake (required for the cardiovascular risk factor and ethnicity project below).

The GPs agreed to complete these data, especially the background variables and the problem lists, which also include historical medical information from before the start of the project, for three years.

The population in the central data base created in this way, shows about the same distribution in terms of age, sex, and ethnic background as the total population of the region.

Because there is always a considerable variation in morbidity and registration amongst practices, the municipal health service aims to enlarge the number of participating practices from 14 to 25 or 30 to increase the representativity of the findings. ${ }^{7}$

The participating GPs no longer record patient information on written records so data on the reasons for consultation, complaints, symptoms, diagnoses, referrals, laboratory findings, medication etc, are entered on the computer too. This means that the project may be extended in the future and offers the possibility of addressing a wide variety of research questions.

\section{Quality control}

Four instruments are used to assess and increase the quality of the data.

Firstly, monthly meetings of participating GPs are held, during which specific registration questions based on their experience are discussed. The GPs can ask questions on their own initiative or may be asked by the municipal health service to present a specific problem that they have recorded on a problem list. Two types of questions are dealt with during these meetings. The first type is along the line of: "Should I or should I not record a problem on the problem list in this specific situation?" The second type can be characterised by: "Which label should I give to this problem?" For the second type of question the diagnostic criteria, as defined in some protocols of the Dutch College of General Practitioners, ${ }^{8}$ are helpful.

The second instrument is the ICPC software module. The Departments of Medical Informatics and General Practice, Erasmus University participated in a project to develop this module. It consists of a thesaurus and a search algorithm to define the most probable ICPC code. The module is now available to all interested Dutch GPs. This ICPC software module is operational in most participating practices. It helps the GPs find the most appropriate ICPC code, given their description of the problem, and its use increases the coding uniformity among the participating doctors.

Thirdly, the municipal health service carries out data checks on the files received from the GPs every three months. Missing and inconsistent data are controlled for.

Finally, there are several data checks. At this moment, for example, the accuracy of the vital status of the patients included in the registry is being assessed, and the designated ICPC codes of causes of death are being validated.

\section{Project: cardiovascular risk factors and ethnicity}

Little is known about the distribution of cardiovascular (CV) risk factors, morbidity, and mortality within the different ethnic groups in The Netherlands. The most important ethnic minorities in Rotterdam are as follows: people from Surinam (a former Dutch colony in South America), Turkey, Morocco, and Asia (predominantly from Indonesia and China).

At the beginning of 1992, six GPs who had participated in the project from the start and with whom about 28000 patients were registered, were asked to record prospectively the CV risk factors in all men aged $40-70$ years who consulted them. Data included body mass index, smoking habits, alcohol use, history of ischaemic heart disease, family history of ischaemic heart disease, blood pressure, and serum cholesterol concentration. In this pilot study we aimed at assessing whether the GPs could record information for specific projects in addition to their regular data recording.

The data presented are restricted to men aged $40-55$ years because there were very few Moroccan and Turkish men older than 55 years. At the start of the project about $25 \%$ of their $\mathrm{CV}$ risk factors were registered in the computers of the participating GPs. The situation in mid 1994 is presented in the table.

The study population consisted of 2503 men aged $40-55$ years. The ethnic background is 
Cardiovascular risk factors in relation to ethnicity in men aged 40-55 years

\begin{tabular}{lrclll}
\hline $\begin{array}{l}\text { Country of } \\
\text { origin }\end{array}$ & $N o^{*}$ & $\begin{array}{l}\text { Hypertensiont } \\
(\%)\end{array}$ & $\begin{array}{l}\text { Body mass index } \\
>30 \mathrm{~kg} / \mathrm{m}^{2}(\%)\end{array}$ & $\begin{array}{l}\text { Cigartte } \\
\text { smokers (\%) }\end{array}$ & $\begin{array}{l}\text { Hypercholesterol- } \\
\text { aemia (\%) }\end{array}$ \\
\hline Netherlands & 1961 & 9 & 13 & 42 & 9 \\
Surinam & 44 & $20 \ddagger$ & 5 & 30 & 7 \\
Morocco & 40 & -5 & 17 & 54 & -5 \\
Turkey & 44 & 17 & $30 \ddagger$ & $73 \ddagger$ & 70 \\
Asia & 54 & 7 & -5 & 40 & 9 \\
Totall & 2503 & 10 & 13 & 42 & 9
\end{tabular}

* Values are known for from $38 \%$ (body mass index) to $76 \%$ (hypertension).

† According to the criteria of the Dutch College of General Practitioners: diastolic pressure $\geq 95 \mathrm{mmHg}$, assessed at least five visits with two measures at each visit, over a period of three to six months; or diastolic pressure $\geq 105 \mathrm{mmHg}$, assessed during at least three visits with two measures in each visit, over a period of some weeks to three months.

$¥$ Significant difference from the percentage of the Dutch men $(p<0 \cdot 05)$.

Number of patients with known value too small.

Including other lands of origin. known for 2258 men: there were 1961 Dutch, 54 Asian, 44 Surinam, 40 Moroccan and 44 Turkish men. Risk factors were recorded ranging from $38 \%$ (body mass index) to $76 \%$ (blood pressure). Although the numbers of patients in some of the ethnic groups are still relatively small, striking differences are apparent. A significantly higher proportion of Turkish men smoke or have a body mass index $>30 \mathrm{~kg} / \mathrm{m}^{2}$, or both, compared with Dutch men aged $40-55$ years. Significantly more men from Surinam have hypertension.

The project has now been extended to include more GPs and therefore more patients from the ethnic minority groups.

The central data base as a starting point of research and prevention

As mentioned in the section on data collection, more data than are being used routinely are available from the GP's practice computers. For example, the central data base can be used to identify patients according to certain diagnoses or symptoms (or, soon, prescribed medications) to initiate specific research projects.

There are also, however, possibilities beyond the area of scientific research. The CV project, for example, is not only a scientific project. The Municipal Health Service Rotterdam will use the results to prepare preventive activities aimed at the different ethnic minority groups which are generally in a disadvantageous socioeconomic and health position.

Computerised practices not only offer the opportunity for investigations but also enable the initiation of new preventive activities and the improvement of existing ones. The GPs can develop and implement these themselves, but the municipal health service can support them. In the $\mathrm{CV}$ project, the municipal health service was able to provide doctors with a list of patients with unknown serum cholesterol concentrations, although according to the cholesterol protocol of the Dutch College of General Practitioners ${ }^{8}$ this should have been measured.

Another example is cervical cancer screening. In most parts of The Netherlands, screening is carried out by the local Municipal Health Service, which invites women aged $35-53$ years (by a personal letter) to contact their physician for a cervical smear. In Rotterdam, the response is about $50 \%$, as it is elsewhere in The Neth- erlands. In fact, more than $50 \%$ of the women are protected, because the $50 \%$ non-response rate includes women who have had a recent smear or who have had a hysterectomy. The response is still too low, however, since it is known that the a priori risk of cervical cancer is higher in non-responders than responders. One of the practices in our region has a postal reminder system and achieves a response of about $80 \% .{ }^{9}$ Together with some of the computerised practices, the Municipal Health Service Rotterdam is implementing a system in which a reminder letter will be sent by the GP to women on his list who have not responded to the invitation from the health service. The central data base of ROHAPRO has therefore enabled efficient tracing of women who had not responded to an invitation to visit their GP.

With the availability of computerised general practices, additional possibilities for other community based projects, such as a call and reminder system for influenza vaccination, are offered. Non-response (who and why) can be monitored and follow up research within the data base ${ }^{10}$ can be performed.

Other possibilities are considered, varying from more intensive communication between the health service and the GP to the installation of electronic mail for the notification of infectious diseases. If these diseases are recorded properly, it would even be possible to make notifications completely automatic.

We believe that a computerised network of general practices, such as ROHAPRO, offers many opportunities to strengthen the link between public and primary health care and to improve the prevention activities of both GPs and the public health services.

We are grateful to the GPs participating in ROHAPRO C H Baar, A J E Beek, G W A M Bles, H J Bueving, W van Dam $P$ van Dijk, Th R M Q Enneking, H E Hart, $K$ Hentzen,

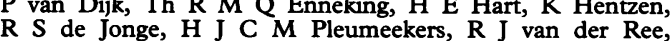
G C J M van Rooy, W A M Schramade, A N P L Verhoeks and J van Vreedendaal. We thank E H Prins for his critical comment on an earlier draft.

1 Ministerie van WVC. Wet collectieve preventie. Rijswijk: Min isterie van WVC, 1990. (Ministry of Welfare, Public Health and Culture. Collective prevention law. Rijswiik: Ministry of Welfare, Public Health and Culture, 1990).

2 Van der Lei J, Duisterhout JS, Westerhof HP, et al. The introduction of computer-based patient records in the Netherlands. Ann Intern Med 1993;119:1036-41,

3 Höppener P. Automatisering en wetenschappelijk onderzoek in de huisartspraktijk (Automation and scientific research in general practice). Maastricht: University of Limburg 1990 general practice). Maastricht: University of Limburg 1990,

4 Metsemakers, JFM. Unlocking patients' records in general practice for research, medical education and quality assurance: the registration network family practices. Maastricht: University registration network family practices.

5 Sandlow LJ, Bashook PG. Problem oriented medical reconds: self instruction for practitioners. Chicago: Michael Rees Hospital and Medical Center, 1978.

6 Lamberts H, Wood M. ICPC: International Classification of Primary Care. Oxford: Oxford University Press, 1987.

7 Van der Zee J, Van Leeuwen P, Bartelds AIM. Recording habits of sentinel practices. In: Bartelds AIM., Fracheboud $\mathrm{J}$, Van der Zee J. The Dutch sentinel practice network; nelevance for public health policy. Utrecht: Netherlands Institute of Primary Health Care, 1989;27-51.

8 Rutten GEHM, Thomas S, eds. NHG-standaarden voor de huisarts (Standards of the Dutch College of General Practitioners). Utrecht: Bunge, 1993.

9 Prins A. Bevolkingsonderzek op baarmoederhalskanker. Resultaten na drie jaar uitnodigen tot deeleme vanuit huisarten na drie jaar uitnodigen tor deelname vanuit de huisartspraktijk. (Screening on cervical cancer. Results after three years of calling up from a general practice).
Medisch Contact 1993;48:537-8 [In Dutch]. 10 Govaert TME Dinant GJ, Knot [n Dutch]

influenza in influenza in een huisartsprakt)k (Influenza vaccination in a general practice). Huisarts en Wetenschap 1991;34:478-81 [In Dutch, with an abstract in English] 